\title{
Analysis of Heat Transfer, Friction Factor and Exergy Loss in Plate Heat Exchanger Using Fluent
}

\author{
Shive Dayal Pandey*, V. K. Nema \\ Department of Mechanical Engineering, M.N. National Institute Technology, Allahabad, 211004 (U.P), India
}

\begin{abstract}
Exergy analysis and energy saving are very important parameters in the heat exchanger design. The effects of surface geometry on heat transfer, friction factor and exergy loss were investigated analytically using fluent software for a flat plate heat exchanger. The analysis was carried out for a 1-1 pass heat exchanger under parallel and counter flow situations, for turbulent flow conditions. Both the heat exchanging fluids were water. It is found that the exergy loss increases with increase in the mass flow rate. Heat transfer rate increases while friction factor and thereby pressure loss decreases with increase in Reynolds number. The various correlations for a flat PHE obtained using fluent $\operatorname{are} N u / \operatorname{Pr}^{1 / 3}=$ $0.0108 \mathrm{Re}^{0.895}$ and friction factor $\mathrm{f}=55 \mathrm{Re}^{-0.87}$. Pressure drop greatly increases the capital cost though heat transfer has larger effect on the exergy loss. For improving the heat transfer between the plates and minimizing the exergy loss, the analysis with the software may prove useful in the optimization method for selecting parameters of the plate heat exchangers.
\end{abstract}

Keywords Plate Heat Exchanger (PHE), Exergy, Modeling, Analysis, Friction Factor, Pressure Drop, Fluent

\section{Introduction}

The most common variant of the plate and frame heat exchanger consists of a number of pressed corrugated metal plates compressed together into a frame. These plates are provided with gaskets, partly to seal the spaces between adjacent plates and partly to distribute the media between the flow channels. The most common plate material is stainless steel. Plate and frame heat exchangers were first used in the food and dairy industries, where the ability to access plate surfaces for cleaning is imperative. Plate and frame exchangers can accept more than two streams, but this is unusual. Two-pass arrangements are, however, common. Figure. 1 illustrates the flow path in such a unit[1]. Numerical and experimental investigations of flow and heat transfer in narrow channels with corrugated walls need exploring the possible method of heat transfer augmentation efficiently. Application of this corrugated wall type equipment in industry is continuously increasing; the necessary knowledge for modeling and optimization of their performance is still limited. A commercial CFD code $\left(C F X{ }^{\circledR}\right.$ 5.7) was used in References[2,3] to simulate the performance of a model heat exchanger comprising of equivalent flat plates, for both single pass parallel and counter flows. The CFD simulation is validated using

* Corresponding author:

pandeyitbhumech@gmail.com (Shive Dayal Pandey)

Published online at http://journal.sapub.org/ep

Copyright (C) 2011 Scientific \& Academic Publishing. All Rights Reserved experimental data on pressure drop and overall temperature differences acquired for counter current flow of water at both sides of the model heatexchanger for various hot fluid flow rates (corresponding to a Reynolds number range from 1500 to 2300 ). The temperatures at various locations along the hot and the cold sides of the heat exchanger are measured by nine thermocouples. Since the type of flow prevailing in these type of conduits is considered to be turbulent, even for the Reynolds number range employed in this study, the most appropriate turbulence model must be chosen by taking into account both the complexity of the geometry and the restrictions induced by each computational model available in the CFD code. In this way, the SST (Shear-Stress Transport) model is selected, which is a combination of two well-known turbulence models, i.e. $k-\varepsilon$ and $k-\omega$. The results of this study, presented in terms of friction factor, wall heat flux and heat transfer coefficients, are compared with the collected experimental data and suggest that the CFD code is capable of predicting the flow and heat transfer characteristics in this kind of complex geometries. It must be also noted that the limited results of relevant experimental and theoretical works reported in the literature are found to be in fairly good agreement with the results of this study, which is currently in progress[2,3]. 


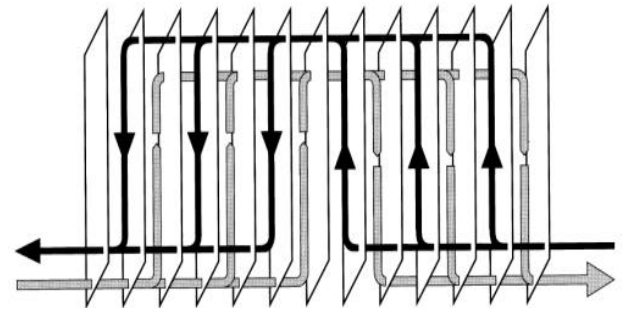

Figure 1. A two-pass plate and frame flow arrangement.

In optimization of plate type heat exchanger, the objective function is to achieve a minimal total annual cost of heat exchangers to determine the optimal dimensions of the apparatus with the given conditions of equipments operation. The pressure drops of both the heated gas and cooled gas determine the power consumption for fans and thus influence operating costs. Heat transfer rate and pressure drop are directly related. Higher pressure drop results in an increase in the power requirement and coupled operating costs. The optimum dimensions of the heat exchangers are calculated using the evaluation of surface area $A$, where $U$ is a function of values of $h_{1}$ and $h_{2}$ and relations among geometrical parameters. The objective function used for the optimization is a nonlinear function with two independent variables $h_{1}$ and $h_{2}$ with continuous derivatives. A suitable computer program can improve the optimization procedure. The problem, which can be described by the equation, can also be solved by using an advanced optimization approach like GAMS (General Algebraic Modeling System) which is widely used with different computer platforms. The benefits of the presented optimization approach are illustrated through the practical examples of different industrial units from a real operation. Results show the potential saving if the optimization approach is used. Applying this method in practice requires following technological and economical conditions, taking into consideration the characteristics of burners, flue gas and air ducts; plate heat exchangers manufacturer limitations and cost data changes in various specific cases. The system GAMS is used for validating optimization procedure based on Newton-Raphson method and for further improving the optimization approach[4,5]. A model is developed to study the influence of the configuration of a plate heat exchanger on the equipment performance and to further develop a method for optimizing the exchanger configuration, through assembling algorithm, since it is not possible to represent the model explicitly as a function of the six parameters. The resulting system is composed of ordinary differential equations of the boundary value type, which is solved by the finite difference method, using the software GPROMS (process systems enterprise, 2001). The main simulation results are the following: temperature profile in all channels, thermal effectiveness, distribution of the overall heat transfer coefficient along the exchangers and fluid pressure drop. Examples of heat exchangers with approximately 150 plates yield algebraic models with thousands of equations which are solved within minutes. The configuration of PHE was characterized by a set of six parameters and a methodology to detect equivalent configuration was presented. Based on this parameterization, a detailed model for the simulation of a PHE in study state with a general configuration was developed in algorithmic form. The developed assembling algorithm made the simulation and comparison of different configuration more flexible. An important feature of the proposed algorithms is that it may be coupled to any procedure to solve the system of differential and algebraic equations. The presented algorithm is an important tool for the study of the influence of the configuration over the exchanger performance and can be further used to develop an optimization method for selecting the PHE configuration. A research in this subject is currently in development[6].

The research methodologies, for studying the effects of operating conditions on calcium carbonate fouling in a Plate Heat Exchanger included the computer simulation, using Computational Fluid Dynamics (CFD) and the experimental works with this objective. COMSOL MULTIPHYSICSTM Version 3.3 was used to simulate the velocity flow fields to verify the low and high flow regions. The results from the CFD technique were then compared with the images obtained from the experiments in which the fouling test rig was set up with a single channel plate heat exchanger to monitor the fouling of calcium carbonate. The results indicated that the velocity distribution for the case of 55/55 degree seems to be very well organized when compared with the others. Also, an increase in the inlet velocity resulted in the reduction of fouling rate on the surface of plate heat exchangers. The research methodologies were the computer simulation using Computational Fluid Dynamics (CFD) and the experimental works for finding fluid distribution and flow pattern in a plate heat exchanger at different feed inlet velocity and crossing angles of plate heat exchanger. The simulation results agreed very well with the experimental results. Both approach show that the high feed inlet velocity and the high crossing angle could reduce fouling significantly. The fouling tended to occur around the dead spot of low velocity and circulation. Thus for the GX-12 plate, the recommended design was the using of the crossing angle of $55 / 55$, and the feed of $0.1698 \mathrm{~m} / \mathrm{s}$ [7].

A screening method for the optimal selection of plate heat exchanger configurations was developed in the reference[8]. It is an optimization method for determining the best configuration(s) of gasketed plate heat exchangers. The objective is to select the configuration(s) with the minimum heat transfer area that still satisfies all the constraints. The optimization method is able to successfully determine a set of optimal configurations with a minimum number of exchanger evaluations. Approximately $5 \%$ of the pressure drop and channel velocity calculations and $1 \%$ of the thermal simulations are required for the solution. It was verified that the number of channels per pass has a strong effect on the pressure drop, and consequently, about $98 \%$ of the elements in IS are eliminated in the first part of the screening (steps 1 through 8). Compared to an exhaustive enumeration procedure, the screening method demands 
approximately $5 \%$ of the required evaluations. The problem of optimizing the PHE configuration was formulated as the minimization of the heat transfer area, subject to constraints on the number of channels, the pressure drop and channel flow velocities for hot and cold fluids and the exchanger thermal effectiveness as well as the PHE simulation model [9].

According to experimental results by Aydın Durmus et al. [10], it would be misleading to consider only cost aspect of the design of a heat exchanger. High maintenance costs increase total cost during the services life of heat exchanger. Therefore exergy analysis and energy saving are very important parameters in the heat exchanger design. In this study, the effects of surface geometries of three different type heat exchangers called as PHE flat (Flat plate heat exchanger), PHE corrugated (Corrugated plate heat exchanger) and PHE asterisk (Asterisk plate heat exchanger) on heat transfer, friction factor and exergy loss were investigated experimentally. The experiments were carried out for a heat exchanger with single pass under condition of parallel and counter flow.

\section{Exergy and Exergy Loss Determination}

Exergy transfer effectiveness is used to describe the performance of heat exchangers operating above/below the surrounding temperature with or without finite pressure drop. It is a function of number of heat transfer unit. The ratio of the heat capacity of cold fluids to that of hot fluids and flow patterns on exergy transfer effectiveness of heat exchangers. Furthermore, the results of exergy transfer effectiveness with a finite pressure drop are compared with those without pressure drop when different objective media, such as ideal gas and incompressible liquid, etc. are applied. The detailed comparisons of the exergy transfer effectiveness with heat transfer effectiveness are also performed for the parallel flow, counter flow and cross flow heat exchangers operating above/below the surrounding temperature.

The term exergy is also used, by analogy with its physical definition, in information theory related to reversible computing. Exergy, which is also synonymous with: availability, available energy, exergic energy, exergy (considered archaic), utilizable energy, available useful work, maximum (or minimum) work, maximum (or minimum) work content, reversible work, and ideal work[11]

\section{Theoretical Analysis for Exergy Loss}

Exergy is called the amount of maximum work obtained theoretically at the end of a reversible process in which equilibrium with environment should be obtained.
According to this definition, exergy balance in a steadystate open system can be written as follows:

$$
\begin{aligned}
& E=T_{e} S_{i r r}=T_{e}\left[m_{c}\left(S_{c o}-S_{c i}\right)+m_{h}\left(S_{h o}-S_{h i}\right)\right](1) \\
& d S=\int_{v=\text { const }} \frac{d Q}{T}=\int_{v=\text { const }}^{\cdot} \frac{d U+p d v}{T}=\int_{v=\text { const }} \frac{C d T}{T}
\end{aligned}
$$

For liquids ( $v=$ const.);

Entropy production of adiabatic heat exchangers;

$$
S_{i r r}=C_{h} \ln \left(T_{h o} / T_{h i}\right)+C_{c} \ln \left(T_{c o} / T_{c i}\right)
$$

Exergy loss

$$
E=T e\left[C_{h} \ln \left(T_{h o} / T_{h i}\right)+C_{c} \ln \left(T_{c o} / T_{c i}\right)\right]
$$

$\mathrm{T}_{\text {hi }}, \mathrm{T}_{\text {ho }}, \mathrm{T}_{\mathrm{ci}}, \mathrm{T}_{\text {co }}$ are measured and $\mathrm{E}$ can directly be determined. For liquids $\mathrm{E}$ contains also the exergy loss caused by pressure drop[12]. This project is based on the analytical analysis of plate heat exchanger using Computational Fluid Dynamics (CFD) software 'Fluent'[13].

\section{Modelling of Plate Heat Exchanger}

The Modelling of the plate heat exhangers through the CFD consists of the following steps:

\subsection{Model Generation}

First plates of desired dimensions are made with the GAMBIT software:

The respective dimensions were given manually and the developed first plate in shown in the Figure. 2. The process was repeated for the other two plates.

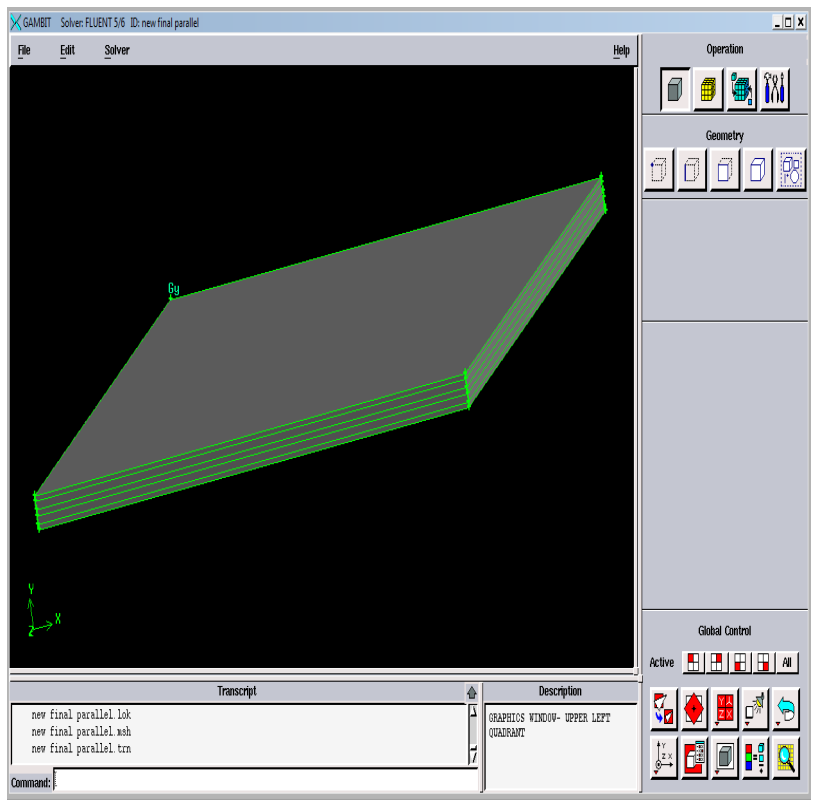

Figure 2. Plates of desired dimensions.

\subsection{Mesh/Grid Formation}

After making the model, the meshes are generated: Mesh generation process is shown in Figsure. 3 and 4. 


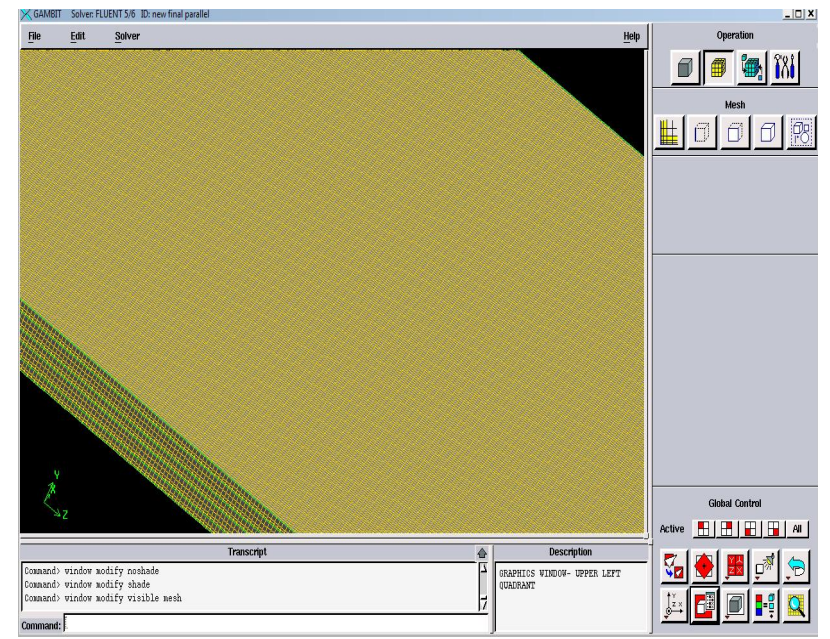

Figure 3. Meshes are generated.

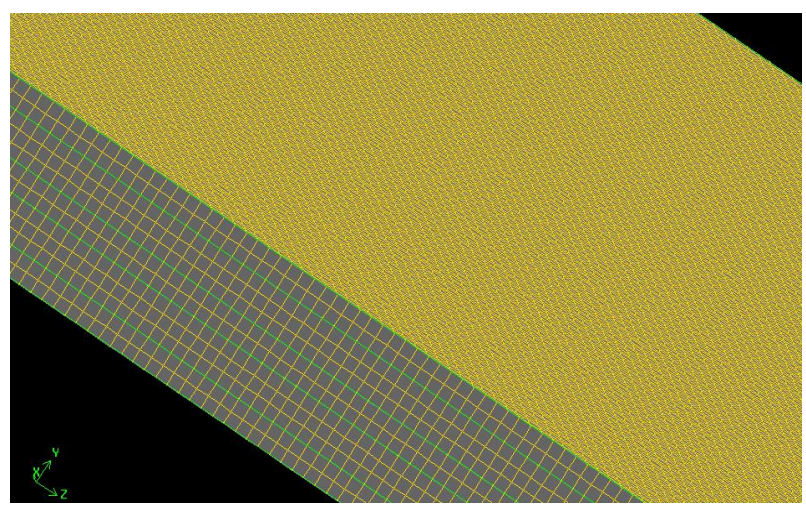

Figure 4. Meshes are generated.

\subsection{Define Continuum}

In this step the solid plates and liquids (for heat exchanging fluid) are defined:

White color is chosen to represent plate solid surface and yellow for fluid. The sequence from top to bottom is top most plate, hot fluid, intermediate plate 1, cold fluid, intermediate plate 2, hot fluid and then the bottom most plate. Providing the input accordingly, the information is displaced as shown in the table in the inset of Figure. 5. The entire plates and fluids are also shown in the same Figure.

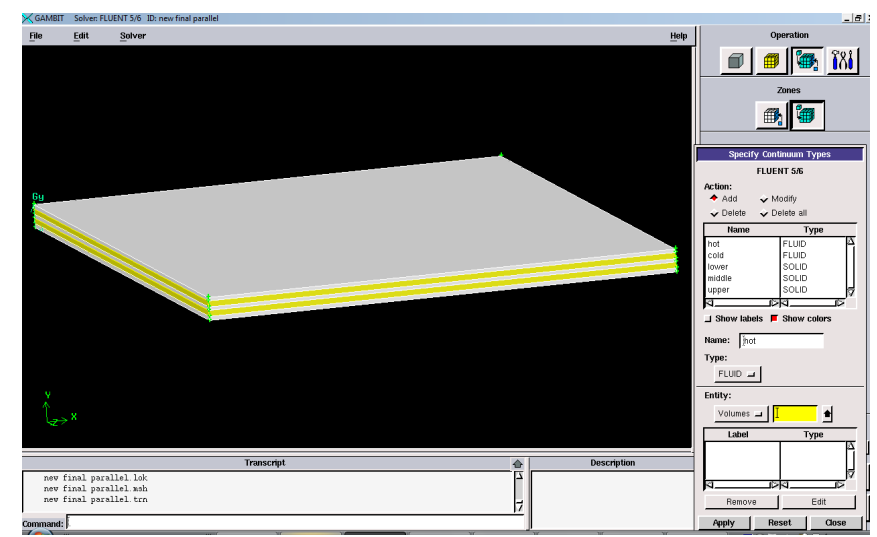

Figure 5. Plates and Fluid.

\subsection{Apply the Boundary Conditions}

One of the flow properties is specified at the either end of the heat exchanger. It may be the fluid pressure, velocity or mass flow rate.

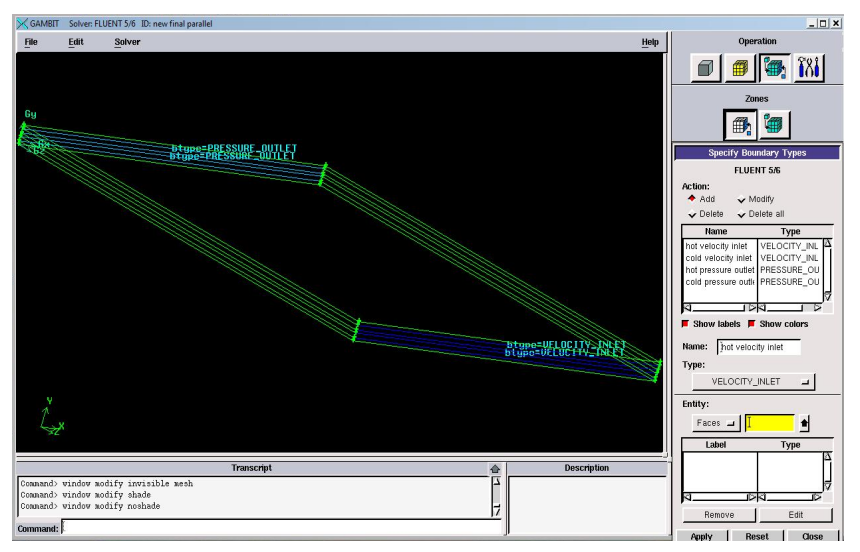

Figure 6. Parallel flow condition.

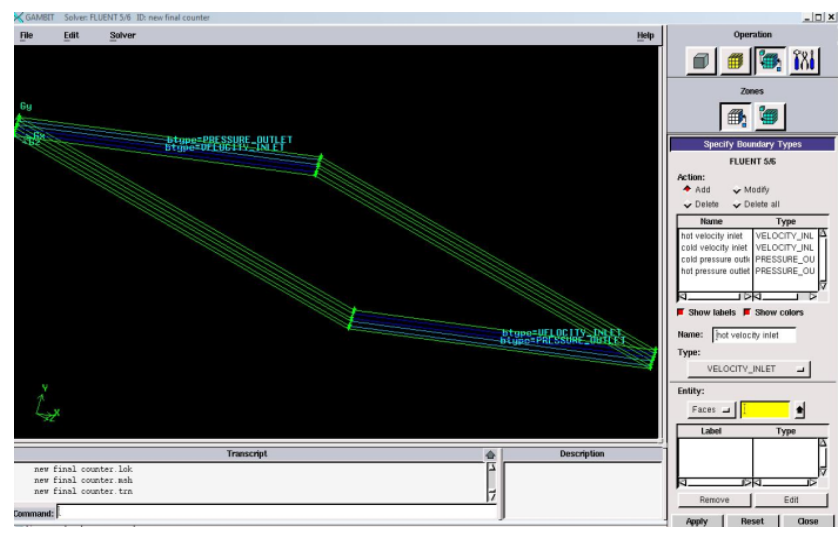

Figure 7. Counter flow condition.

For parallel flow situation, velocities of incoming hot and cold fluids are used to define the variables at one end and pressure of out- going hot and cold fluids at the other end. These four variables are indicated by hot velocity inlet cold velocity inlet, hot pressure outlet and cold pressure outlet in the inset of Figure. 6. These variables are modified for counter flow situation and are shown in the inset of Figure. 7.

\section{Results and Discussion}

The CFD analysis is made under the following assumption:

\subsection{Assumption}

- The Physical properties are fixed based, for example, on inlet conditions.

- The inlet temperatures are uniform at the inlet and outlet sections.

- Behavior of each flow stream is treated the same i.e their Reynolds number, velocity and film heat transfer coefficient are equạl.

- Mass flow $m$ (for each stream) remains same from inlet to outlet of the PHE. 
Wall temperature, length of the exchanger and ambient temperature are invariant along the PHE.

- Adequate insulation is provided so that heat given by hot fluid is fully absorbed by the cold fluid.

In view of these assumptions the constants used are the thermophysical properties $\mathrm{K}, \mu, \rho, \mathrm{c}_{\mathrm{p}}$ and $\mathrm{H}$.

Further the variables used may be classified in to the following:

Dependent variables: f, $\mathrm{Nu}, \mathrm{Pr}, \mathrm{S}, \mathrm{E}, \mathrm{D}_{\mathrm{h}}$ and Q.

Independent variables: $\mathrm{V}, \mathrm{A}, \mathrm{P}, m, \mathrm{Re}, \mathrm{T}_{\mathrm{hi}}, \mathrm{T}_{\mathrm{ho}}, \mathrm{T}_{\mathrm{ci}}$ and $\mathrm{T}_{\text {co. }}$

\subsection{Equation Used}

The following equations have been used;

Heat loss/gain by fluids

$$
Q=\left(\dot{m} c_{p}\right)_{h}\left(T_{h i}-T_{h o}\right)=\left(\dot{m} c_{p}\right)_{c}\left(T_{c o}-T_{c i}\right)
$$

Reynolds Number

$\mathrm{Re}=\rho \mathrm{V} \mathrm{D} / \mu$

Fluids properties are evaluated at mean temperature given by

$$
\begin{aligned}
& T m, c=(T c o+T c i) / 2 \\
& T m, h=(T h i+T h o) / 2
\end{aligned}
$$

For adiabatic heat exchanger

$$
Q=H_{h} A \Delta T_{h}=H_{c} A \Delta T_{c}
$$

The Nusselt numbers, in terms of the cold or hot water side are

$$
N u=H D_{h} / k
$$

Exergy loss

$$
\begin{gathered}
E=T_{e} S_{i r r}=T_{e}\left[m_{c}^{\prime}\left(S_{c o}-S_{c i}\right)+m^{\prime}{ }_{h}\left(S_{h o}-S_{h i}\right)\right] \\
d s=\int_{v=\text { const }} \frac{d Q}{T}=\int_{v=\text { const }} \frac{d U+p d v}{T}=\int_{v=\text { const }} \frac{C d T}{T}
\end{gathered}
$$

Entropy production of adiabatic heat exchangers

$$
\begin{aligned}
& S_{i r r}=C_{h} \ln \left(T_{h o} / T_{h i}\right)+C_{c} \ln \left(T_{\mathrm{co}} / T_{c i}\right) \\
& E=T e\left[C_{h} \ln \left(T_{h o} / T_{h i}\right)+C_{c} \ln \left(T_{\mathrm{co}} / T_{c i}\right)\right]
\end{aligned}
$$

Pressure drop

$$
\Delta p=\frac{f l v^{2}}{d 2 g}
$$

Hydraulic diameter

$$
D_{h}=4 A_{c} / P
$$

Prandtl Number

$$
\operatorname{Pr}=\mu C_{p} / K
$$

Mass flow rate

$$
\dot{m}=\rho A V
$$

\subsection{Exergy Loss and Mass Flow Rate}

\subsubsection{By Analytical Reults}

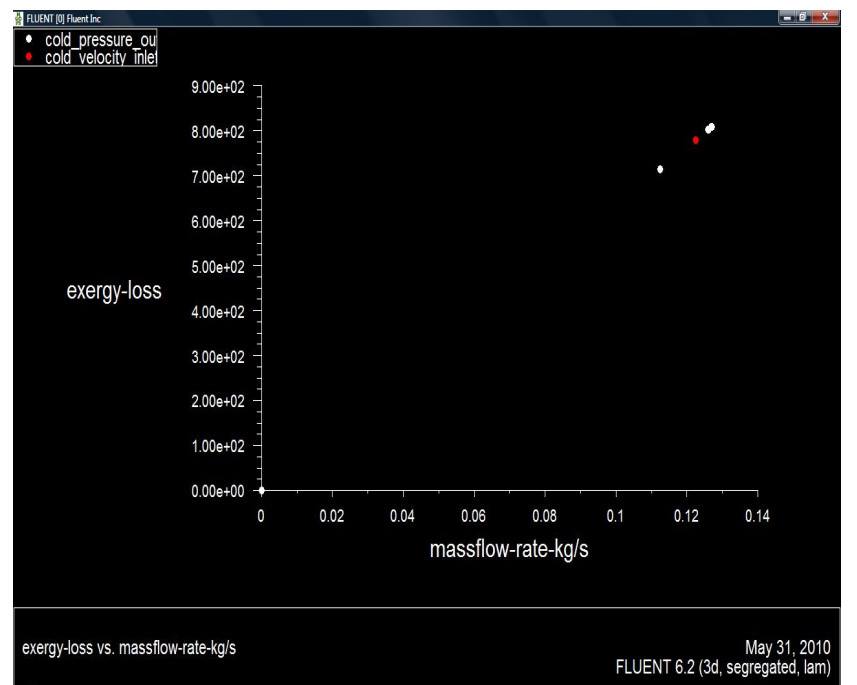

Figure 8. Variation of Exergy loss with hot water mass flow rate.

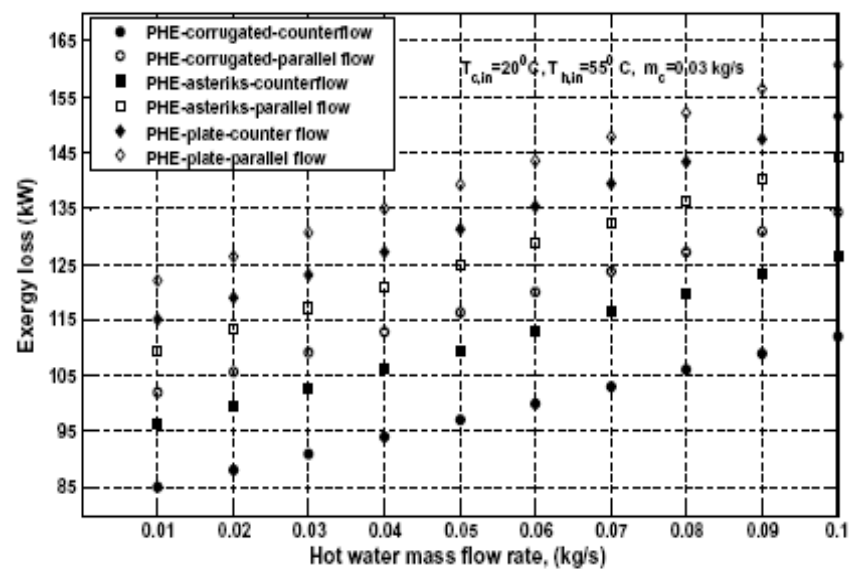

Figure 9. Variation of Exergy loss with hot water mass flow rate.

Variation of the exergy loss with hot water mass flow for a flat PHE as obtained by using the fluent for same cold water flow rate as taken in the reference[10] is shown in the Figure. 8. This is approximately similar to the experimental result shown in Figure. 9 for PHEs of various configurations for parallel and counter flows situations. The loss can be optimized by varying the mass flow rate, Reynolds number, cross sectional area, velocity and the working fluid for the same given inlet conditions.

\subsubsection{By Experimental Results}

\subsection{Friction Factor and Reynolds Number}

Variation of friction factor with Reynolds number for a flat PHE using the fluent is shown in the Figure. 10 which is approximately similar to the experimental result shown in Figure. 11 for flat, asteristk and corrugated PHE. The system can be optimized by varying the friction factor, which is a function of Reynolds number. The correlation for a PHE taken up for analytical study for friction factor using fluent, is found as $\mathrm{f}=55 / \mathrm{Re}^{0.87}$. 


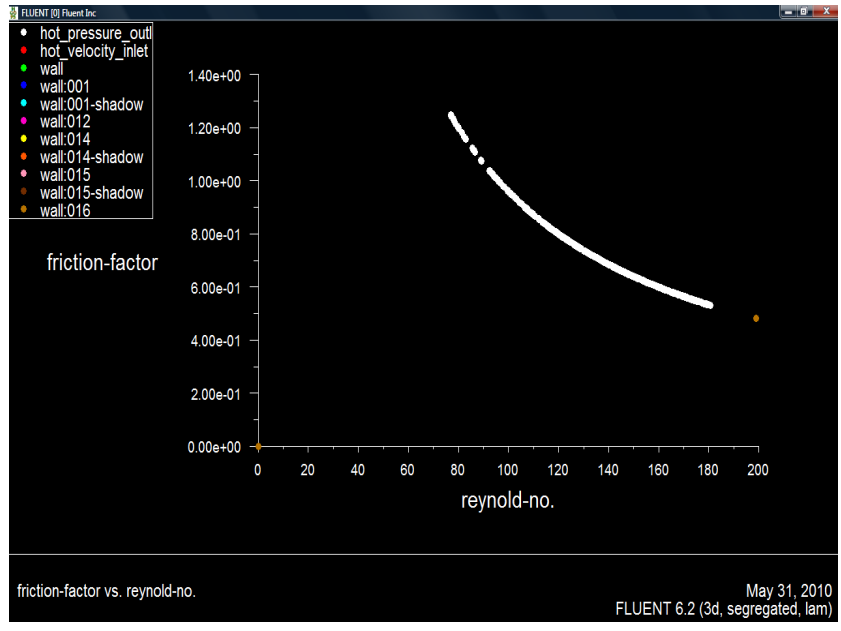

Figure 10. Variation of Friction factor along Reynolds number.

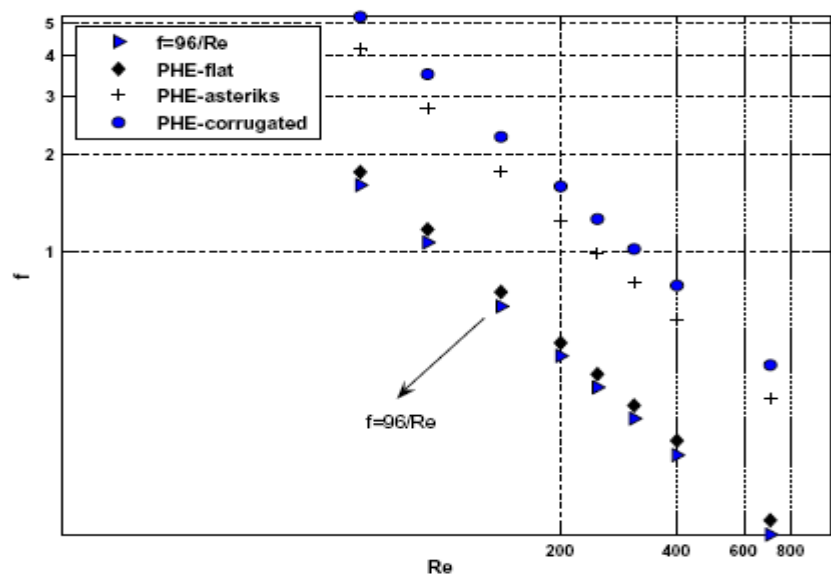

Figure 11. Variation of Friction factor along Reynolds number.

\subsection{The $\mathrm{Nu} / \mathrm{Pr}^{1 / 3}$ and Reynolds Number}

Variations of $\mathrm{Nu} / \operatorname{Pr}^{1 / 3}$ with Reynolds number for the hot and cold side fluids obtained by using the Fluent is shown in the Figures. 12 and 14, which is approximately similar to the experimental results of reference[10] shown in Figures. 13 and 15. It is worthwhile to find a correlation for the analytical case under consideration. The correlation is $\mathrm{Nu} / \mathrm{Pr}^{1 / 3}=0.0108 \mathrm{Re}^{0.895}$.

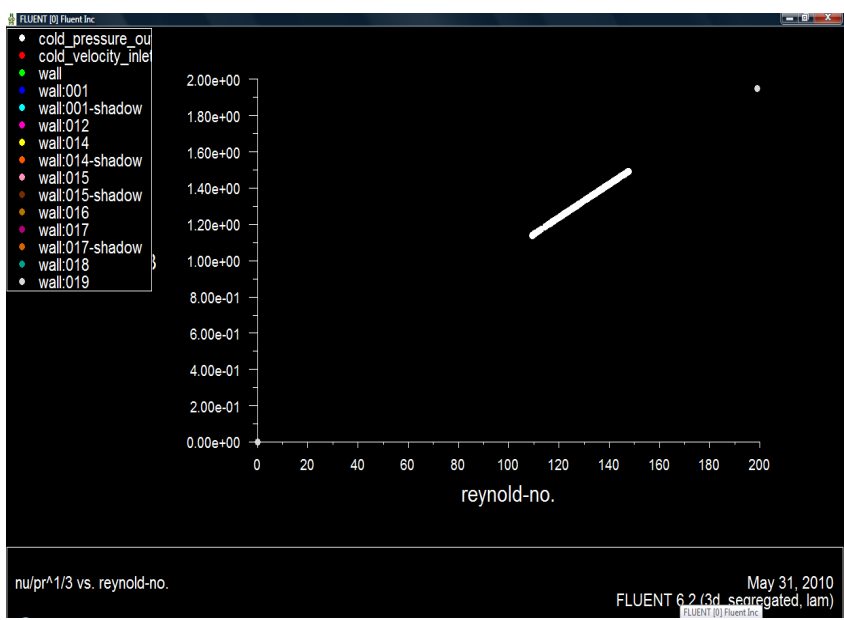

Figure 12. Variation of $\mathrm{Nu} / \mathrm{Pr}^{1 / 3}$ along Reynolds number.

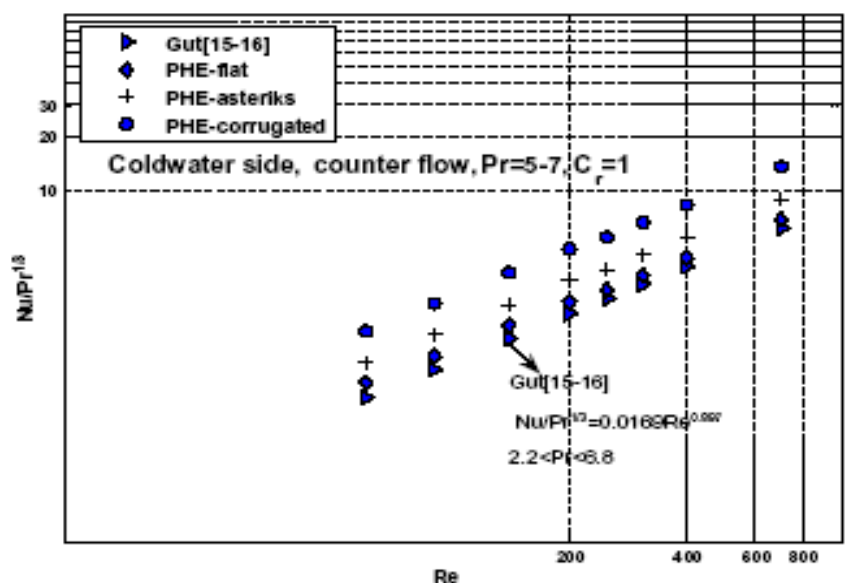

Figure 13. Variation of $\mathrm{Nu} / \mathrm{Pr}^{1 / 3}$ along Reynolds number

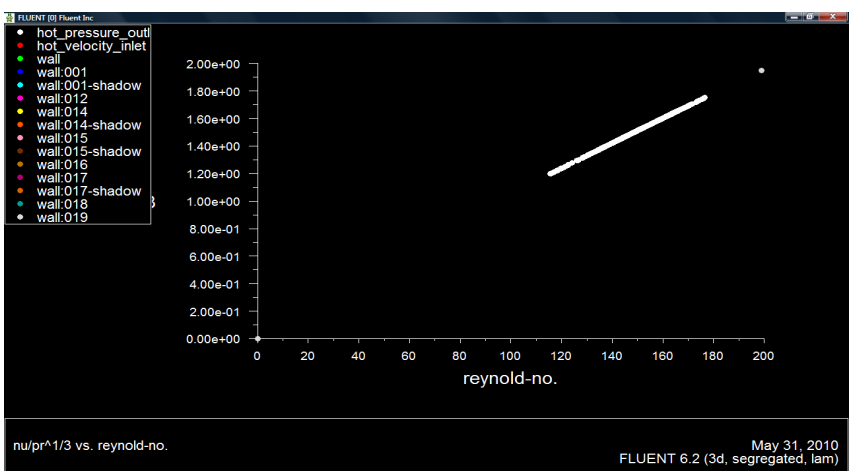

Figure 14. Variation of $\mathrm{Nu} / \mathrm{Pr}^{1 / 3}$ along Reynolds number.

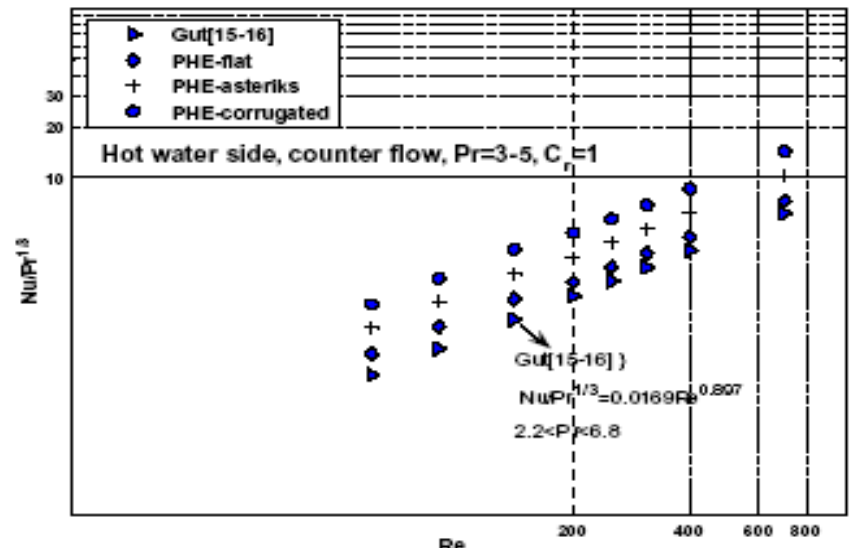

Figure 15. Variation of $\mathrm{Nu} / \mathrm{Pr}^{1 / 3}$ along Reynolds number.

\section{Contour of Temperature Variation}

The contours of temperature distribution over the whole plate length for counter and parallel flows are shown above and from these contours, the temperature distribution can be determined which is helpful in selecting the plate material.

In parallel flow, hot water and cold water flow from right to left. So, upper and lower plate temperatures are high on right end of the plates as shown in the Figure. 16. In counter flow hot is made to enter the right end of cannel and hence highest temperature is obtained on the right end of the plate, which may be seen in Figure. 17. 


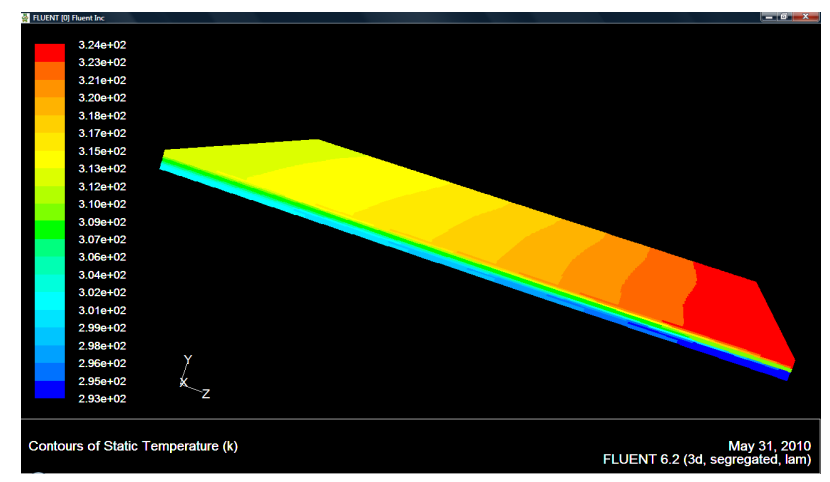

Figure 16. Parallel flow.

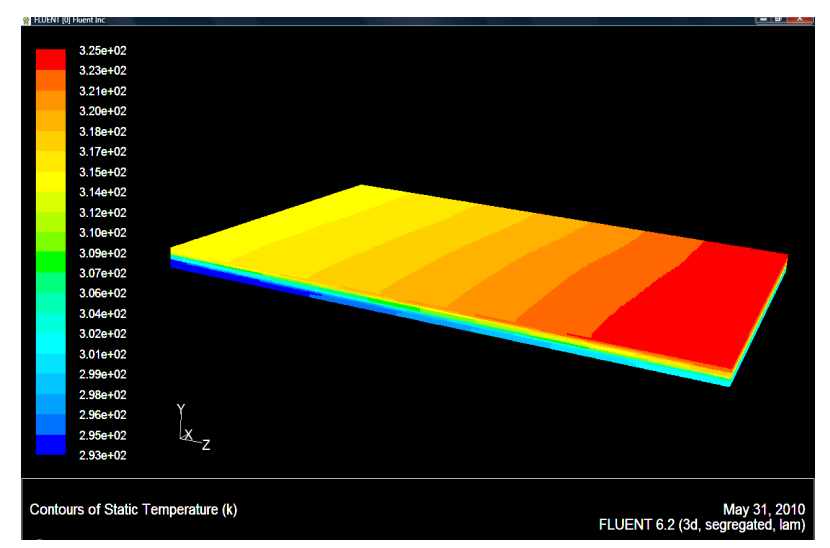

Figure 17. Counter flow.

\section{Contours of Pressure Variation}

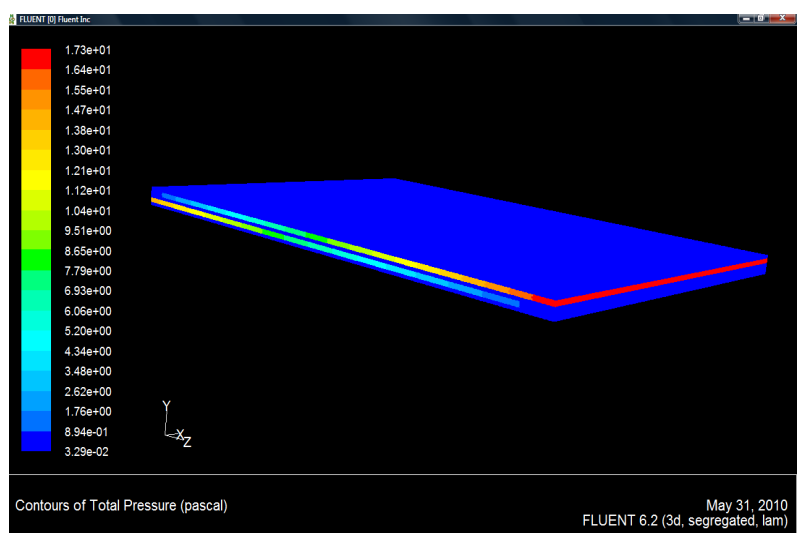

Figure 18. Counter flow.

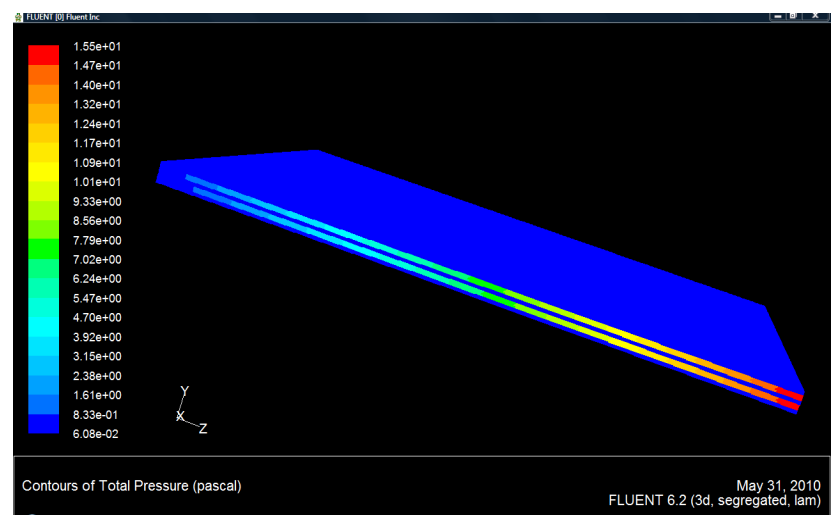

Figure 19. Parallel flow.

The contours of pressure distribution over the whole plate length for counter and parallel flows are shown in the Figures. 18 and 19, respectively.

\section{Conclusions}

The results obtained from analysis by CFD are coming nearer to the experimental results. The software gives the useful information about the exergy-loss, friction factor, pressure drop and other parameter. The analysis was carried out for the heat exchanger with single pass under conditions of parallel and counter flows, for turbulent flow conditions. Both the heat exchanging fluids were water. It is found that the exergy loss increases with increase in the mass flow rate. Heat transfer rate increases and friction factor hence pressure loss decrease with increase in Reynolds number. The various correlations obtained for flat PHE using fluent are $\mathrm{Nu} / \mathrm{Pr}^{1 / 3}=0.0108 \mathrm{Re}^{0.895}$ and friction factor $\mathrm{f}=55 \mathrm{Re}^{-0.87}$. Pressure drop greatly increases the capital cost though heat transfer has larger effect on the exergy loss. For improving the heat transfer between the plates and minimizing the exergy loss, the analysis with the software may prove useful in the optimization method for selecting parameters of the plate heat exchangers.

\section{Nomenclature}

A

$\mathrm{D}_{\mathrm{h}}$

$\mathrm{E}$

$\mathrm{f}$

L

$\mathrm{Nu}$

$\mathrm{Pr}$

Q

Re

$\mathrm{T}$

$\mathrm{H}$

U

$\rho$

$\mu$

$\mathrm{c}_{\mathrm{p}}$

$\mathrm{K}$

$\mathrm{m}$

$\mathrm{S}$

$\mathrm{S}$

V

Suffix

e Ambient or environment

i Inlet

o Outlet

w Wall

c Cold

h Hot

m Mean

Exergy, kW

Friction factor

length, $\mathrm{m}$

Nusselt number

Prandtl number

Reynolds number

Temperature, $\mathrm{K}$

Entropy, kJ K ${ }^{-1}$
Cross sectional area, $\mathrm{m}^{2}$

Hydraulic diameter, $m$

Heat transfer rate, $\mathrm{kW}$

heat transfer coefficient, $\mathrm{kW} \mathrm{m} \mathrm{m}^{-2} \mathrm{~K}^{-1}$

Overall heat transfer coefficient, $\mathrm{kW} \mathrm{m} \mathrm{m}^{-2}$

Density of air, $\mathrm{kg} \mathrm{m}^{-3}$

Viscosity of air, $\mathrm{N} \mathrm{s} \mathrm{m}^{-2}$

Specific heat at constant pressure, $\mathrm{kJ} \mathrm{kg}^{-1} \mathrm{~K}^{-1}$

Thermal Conductivity, $\mathrm{kW} \mathrm{m}^{-1} \mathrm{~K}^{-1}$,

Mass flow rate, $\mathrm{kg} \mathrm{s}^{-1}$

Specific entropy, $\mathrm{kJ} \mathrm{kg}^{-1} \mathrm{~K}^{-1}$

Average velocity, $\mathrm{m} \mathrm{s}^{-1}$ 
[7] Suppamassadu, K. P., Jeimrittiwong, P., Narataruksa, P., and Tungkamani, S., Effects of Operating Conditions on Calcium Carbonate Fouling in a Plate Heat Exchanger. World Academy of Science and Engg \& Tech 53, 2009

\section{REFERENCES}

[8] Pandey Shive Dayal, Nema. V. K., Das. M. K., Modeling and Exergy loss reduction in PHEs of typical surface configuration -A review, International Conference on Issues and Challenges in Energy Conversion and Management (ICEM-2009), Narosa publishing corporation, New Delhi, 2009, pp 541-554

[2] Kanaris, A. G., Mouza, A. A., Paras, S. V., 2004, Numerical and experimental investigation of flow and heat transfer in narrow channels with corrugated walls. International Conference from Scientific Computing to Computational Engineering, Athens, 8-10

[3] Muley, A., and Manglik, R. M., 1999, Experimental study of turbulent flow heat transfer and pressure drop in a plate heat exchanger with chevron plates. Journal of Heat Transfer-Transactions of the ASME, 121(1), 110-117

[4] Zdenek Jegla PetrStehlik Josef Kohoutek., 2004, Alternative approach in optimization of plate type heat exchanger. International journal of heat and mass transfer,.25,255-261

[5] Fabbri,G., 2009, Heat transfer optimization in corrugated wall channels, Int. J. Heat Mass Transfer., 43,4299-4310

[6] Gut, J. A. W., Pinto, J. M., 2003, Modeling of Plate Heat Exchanger with Generalized Configurations. International Journal of Heat and mass Transfer, 52, 2571-2585

[9] Aydin Durmus, Huseyin Benli,Irfan Kurtbas, Hasan Gul, 2009, Investigation of heat transfer and pressure drop in plate heat exchangers having different surface profiles. International Journal of Heat and Mass Transfer, 52, $1451-1457$

[10] Perrot, Pierre. A to $\mathrm{Z}$ of Thermodynamics. Oxford University Press. 1998

[11] Hollman, J. P., Heat and mass Transfer. 5th Edition Mcgraw HillNew York ,1995

[12] Pandey. Shive Dayal, Nema. V. K., 2011, Investigation of the Performance Parameters of An Experimental Plate Heat Exchanger in Single Phase Flow, Int. J. of Energy Engineering, 1 (1), 1-6

[13] Reddy, J. N., An Introduction to Finite Element Method, second edition, McGraw Hill, New York, 1993 